Mens

Revue d'histoire intellectuelle et culturelle

mens

Julien Goyette. Temps et culture : Fernand Dumont et la philosophie de l'histoire, Québec, Presses de l'Université Laval, 2017, $251 \mathrm{p}$.

\title{
Daniel Poitras
}

Volume 19, numéro 1-2, automne 2018, printemps 2019

URI : https://id.erudit.org/iderudit/1070081ar

DOI : https://doi.org/10.7202/1070081ar

Aller au sommaire du numéro

Éditeur(s)

Centre de recherche en civilisation canadienne-française

ISSN

1492-8647 (imprimé)

1927-9299 (numérique)

Découvrir la revue

Citer ce compte rendu

Poitras, D. (2018). Compte rendu de [Julien Goyette. Temps et culture : Fernand Dumont et la philosophie de l'histoire, Québec, Presses de l'Université Laval,

2017, 251 p.] Mens, 19(1-2), 233-236. https://doi.org/10.7202/1070081ar d'utilisation que vous pouvez consulter en ligne.

https://apropos.erudit.org/fr/usagers/politique-dutilisation/ 
forme l'identité collective, ce sont les divagations, les pérégrinations des poètes dans cet espace d'infinis où tout devient possible, où l'on parvient à sortir de l'exiguïté (du trou, du manque institutionnel, des trous de langue) pour rentrer dans le futur» (p. 37). Ce passage sur l'identité peut également s'appliquer à la culture, à la littérature. Les figures du poète, de l'écrivain comme du dramaturge sont au cour du processus, tout comme les institutions de la vie culturelle d'ailleurs. Mais pas n'importe laquelle, on l'aura compris: celle d'une culture fondée sur l'identité-relation, sur le rhizome (et non la racine unique), une culture cosmopolite, appelée des vœux de l'auteure: «Il s'agira donc de trouver l'Autre qui est en nous, celui qui fait Relation. Il faudra faire imploser les dichotomies centre-périphérie; dominant-dominé; colonisateur-colonisé. Alors seulement, un monde, que j'appelle cosmopolite, pourra voir le jour» (p. 43). Reste à concilier, dans ce programme, la reconnaissance de l'Autre en nous et cette culture commune. Selon les interprétations du sens donné au terme "cosmopolite», un tel rapprochement pourrait aussi bien mener à une forme d'aporie. À chaque lecteur d'en juger.

Stagiaire postdoctoral à l'Institut d'études acadiennes Université de Moncton

\section{Julien Goyette. Temps et culture: Fernand Dumont et la philosophie de l'histoire, Québec, Presses de l'Université Laval, 2017, 251 p.}

Dans la mer des travaux sur Fernand Dumont, le livre de Julien Goyette apparait comme un roc: il délimite un territoire et s'impose comme un repère incontournable. L'allégorie nautique est en fait bien invitante pour parler de ce livre, puisque c'est en véritable cartographe conceptuel, un œil sur ses cartes, l'autre sur les étoiles et la main sur son sextant, que Goyette nous fait cheminer dans l'œuvre touffue et hétéroclite de Dumont. Mais cette traversée ambitieuse se fait au prix d'un horizon, celui de la terre ferme, et confronte volontiers le lecteur (-historien) qui n'a pas le pied marin (théorique). 
Si la portée d'une œuvre se mesure au nombre d'exégèses qu'elle suscite, celle de Dumont occupe une place à part au Québec. L'une de ses particularités est de receler une quantité impressionnante de développements conceptuels, qui ouvrent simultanément sur la philosophie (ou «anthropologie») de l'histoire et sur le propre itinéraire de Dumont. D'un bout à l'autre de son œuvre, l'intellectuel de l'Université Laval pense et théorise à partir de son ancrage biographique et semble suggérer à tout moment à ses exégètes la trame et les outils pour interpréter sa vie et son œuvre. Face à ce Dumont clés en main qui tendait à transformer son parcours en récit quasi exemplaire de l'histoire collective québécoise (du drame du particulier à l'ironie d'un universel embrouillé), Goyette ne fait pas le pari de la violence externaliste ou celui de la démystification. Pudique sur son propre ancrage, il adopte la posture de l'herméneute et privilégie une approche compréhensive, quoique critique et qui échappe avec succès, doit-on ajouter, à l'instrumentalisation idéologique de Dumont pour un combat ou un autre. Encore a-t-il dû choisir entre le Dumont théorique et «universel» du Lieu de l'homme et le Dumont immergé dans l'histoire de la Vigile du Québec. En accordant toute son attention au premier, le commentateur s'est soustrait aux aléas du genre biographique et aux contraintes de la sociologie des intellectuels pour mieux étudier la «dimension universelle de [la] pensée [de Dumont]» et chercher à «refaire l'unité de son œuvre» (p. 6). Mais ce faisant, Goyette fait beaucoup plus que cataloguer les grands thèmes de la pensée dumontienne; il les actualise aussi grâce à sa propre sensibilité et en rejoue, subtilement, en filigrane, les polarités, les contradictions et même les espoirs et les utopies. Le premier chapitre est, à cet égard, le plus senti: l'auteur nous avoue quelques-unes des tensions, des attentes et des irritations qui ont animé son projet pendant ces longues années en compagnie de l'œuvre de Dumont.

Tout au long de l'ouvrage, Goyette se pose la question suivante: qu'est-ce qui a incité l'intellectuel de l'Université Laval à s'intéresser à l'histoire? C'est en y répondant qu'il répertorie les voies nombreuses qui ramenaient Dumont à l'histoire ou, plus 
précisément, par lesquelles Dumont ramenait l'histoire à ses préoccupations. Déployant sa réflexion dans le temps long (de l'Antiquité à nos jours), utilisant des scènes historiques variées pour tester ses concepts et s'aventurant sur de nombreux terrains (les idéologies, la mémoire, l'épistémologie, l'historiographie, etc.), Dumont n'était peut-être pas un historien (quoique...), mais certainement le chercheur qui, toutes disciplines confondues, a le plus réfléchi à l'histoire (comme expérience et comme discipline) au Québec au $\mathrm{xx}^{\mathrm{e}}$ siècle. La pertinence d'une lecture historienne ou, plus précisément, historiographico-philosophique (celle de Goyette) tombe ici à point: le commentateur propose des passerelles entre la théorie dumontienne et les enjeux qui animent les historiens. Le chapitre «L'épistémologie dumontienne de l'histoire» intéressera particulièrement ceux-ci: on y voit le sociologue de Laval commenter les Annales (et s'en inspirer), actualiser vivement les historiens français du XIX ${ }^{e}$ siècle et tracer des pistes porteuses pour comprendre le rapport de l'historien avec son présent et son futur. En exhumant ainsi le travail historiographique (moins connu) de Dumont, Goyette invite les historiens à davantage de réflexivité sur leur pratique.

S'il n'est pas toujours à propos de critiquer un livre pour les choix qu'il n'a pas faits ou les chemins qu'il n'a pas explorés, c'est souvent difficile d'y résister. Et ce livre s'y prête particulièrement bien. En fait, les conséquences du choix initial de l'auteur (l'œuvre plutôt que la vie) ressortent surtout dans la dernière partie du livre («La mémoire - ou soi-même dans l'histoire»), où Goyette, ici plus que jamais notre contemporain, interprète Dumont en fonction de cette crise de l'histoire et de la culture que le sociologue de Laval a si bien anticipée et décrite. Les inquiétudes de Dumont quant à l'avenir de la mémoire, son rejet d'un certain récit du Progrès combiné à une actualisation tâtonnante et inquiète de la matrice de la modernité à l'ère du présentisme, Goyette les expose avec clarté et nous convainc que Dumont a encore beaucoup à dire aux tourmentés (ou nostalgiques?) de l'Histoire que nous sommes. Mais l'absence du contexte québécois au profit d'un contexte intellectuel aux 
frontières indéfinies enlève à ce chapitre quelque chose comme une caisse de résonance aux idées dumontiennes telles qu'elles se sont déployées dans l'espace et dans le temps. Pour reprendre notre allégorie initiale, le lecteur n'atteint jamais la terre ferme, et ce, même lorsqu'il la sent poindre tout autour de lui, notamment lorsque Goyette parle de l'importance chez Dumont d'une démocratie qui permettrait à tous ceux qui en sont dépourvus de prendre enfin la parole.

Cet amarrage n'était pourtant pas la tâche du cartographe, qui nous plonge plutôt dans cette œuvre immense comme un guide méticuleux et, avec l'aisance du geste synthétique, ne s'embourbe pas dans ses dédales (nombreux et parfois frustrants). Grâce à l'érudition de l'exégète, ce geste déborde l'œuvre de Dumont et nous fait voir quelques-unes des grandes figures et théories de la pensée occidentale qui l'ont nourrie et avec lesquelles (Foucault, Ricoeur, Certeau, etc.) elle a parfois dialogué. Par sa cohérence même, ce travail en appelle en fait un autre qui plongerait Dumont dans les secousses collectives qu'il a vécues et qui l'ont inspiré, c'est la voie que j'ai esquissée dans mon propre livre. Une biographie intellectuelle, donc, qui serait aussi une biographie débordant sur les nombreux engagements de l'intellectuel. Un tel travail dépasserait la seule figure de Dumont et, quitte à aller à rebours de la reconstruction mémorielle qu'il a lui-même serinée, nous donnerait une marge de manœuvre critique pour jauger le déploiement d'un certain récit collectif dans la seconde moitié du $\mathrm{xx}^{\mathrm{e}}$ siècle au Québec. Plus largement, ce travail aborderait de front certaines modalités d'expérience du temps propres au Québec ou, plus précisément, propres au Québec tel qu'il a été pensé et projeté à la confluence des situations locales et des courants transnationaux.

- Daniel Poitras Institut d'histoire de l'Amérique française 